\title{
PENGARUH LINGKUNGAN KERJA DAN MOTIVASI TERHADAP KINERJA PEGAWAI DI KANTOR KECAMATAN WALANTAKA KOTA SERANG
}

\author{
Leny Afrianty ${ }^{1}$, Suflani ${ }^{2}$, Bambang Setyo Panulisan ${ }^{3}$ \\ ${ }^{123}$ Universitas Bina Bangsa \\ lenyafrianty60@gmail.com
}

\begin{abstract}
ABSTRAK
Kantor Kecamatan Walantaka merupakan salah satu kecamatan di kota serang. Sumber daya manusia yang berkualitas sangat penting untuk mencapai tujuan. Selain itu lingkungan kerja dan motivasi menjadi hal yang penting bagi instansi untuk mencapai tujuan organisasi. Tujuan penelitian ini untuk mengetahui pengaruh lingkungan kerja dan motivasi terhadap kinerja pegawai. Jenis penelitian ini menggunakan kuantitatif. Populasi pegawai kecamatan walantak. Sampel yang digunakan yaitu teknik sampel jenuh. Sampel dalam penelitian ini yaitu seluruh pegawai kecamatan walantaka yang berjumlah 30 orang. Pengolah data menggunakan perangkat lunak SPSS 26. Pengujian hipotesis dilakukan dengan uji statistik deskriptif, uji validitas dan reliabilitas, uji asumsi klasik, uji regresi linear berganda, analisis koefisien korelasi, analisis koefisien determinasi dan uji hipotesis statistik uji $T$ dan uji $F$. hasil yang diperoleh dari penelitian ini bahwa lingkungan kerja berpengaruh terhadap kinerja pegawai sedangkan motivasi tidak berpengaruh terhadap kinerja pegawai, dan secara simultan lingkungan kerja dan motivasi berpengaruh terhadap kinerja pegawai.
\end{abstract}

Kata Kunci : Lingkungan kerja, Motivasi, Kinerja Pegawai

\section{ABSTRACT}

The Walantaka District Office is one of the sub-districts in the city of Serang. Quality human resources are very important to achieve the goal. In addition, the work environment and motivation are important for agencies to achieve organizational goals. The purpose of this study was to determine the effect of work environment and motivation on employee performance. This type of research uses quantitative. The population of Walantak sub-district employees. The sample used is the saturated sample technique. The sample in this study were all employees of the Walantaka sub-district totaling 30 people. Data processing using SPSS 26 software. Hypothesis testing was carried out by descriptive statistical tests, validity and reliability tests, classical assumption tests, multiple linear regression tests, correlation coefficient analysis, coefficient of determination analysis and statistical hypothesis testing $T$ test and $F$ test. The results obtained from this study that the work environment affects employee performance while motivation does not affect employee performance, and simultaneously work environment and motivation affect employee performance.

Keywords: work environment, motivation, employee performance 
Prosiding The 1st National Conference on Applied Business, Education, \& Technology (NCABET)",

Unversitas Bina Bangsa 2021

DOI Article : 10.46306/ncabet.v1il.31

\section{PENDAHULUAN}

Sumber daya manusia merupakan asset terpenting disebuah organisasi, baik di bidang instansi pemerintahan maupun di perusahaan. Karena peran manusia menjadi subjek utama atau penggerak untuk melaksanakan segala kebijakan operasional didalam suatu organisasi. Di dalam unsur-unsur manajemen seperti modal, metode, mesin, bahan baku dan pasar tidak bisa memberikan hasil yang maksimal apabila tidak di dukung oleh sumber daya manusia. Hal ini menjadi kunci utama bahwa sumber daya manusia yang harus diperhatikan segala kebutuhannya. Salah satu upaya yang harus dicapai oleh instansi pemerintahan yaitu meningkatkan kualitas sumber daya manusia dengan meningkatkan kualitas maka diharapkan para pegawai dapat meningkatkan kinerja nya.

Di setiap program kerja selama tahun 2020 di Kantor Kecamatan Walantaka Kota Serang, program kerja tersebut tidak sepenuhnya tercapai dengan baik dibuktikan dengan hasil wawancara dengan Sekretaris Camat dan beberapa Pegawai Kantor Kecamatan Walantaka ini masih ada beberapa hambatan seperti kurangnya sumber daya manusia di dalam Kantor Kecamatan Walantaka dan minimnya anggaran sehingga program kerja tidak sepenuhnya tercapai. Selain itu, didalam suatu instansi pemerintahan pasti adanya lingkungan kerja yang mendukung pegawai dalam melaksanakan pekerjaan nya.

Didalam suatu instansi pemerintahan sarana dan prasarana menjadi hal penting untuk menunjang pekerjaan yang ada di dalam suatu instansi, karena dengan adanya sarana dan prasarana yang memadai proses kegiatan kinerja pegawai tersebut dapat tercapai dengan waktu yang tepat. Namun kenyataan nya didalam Kantor Kecamatan Walantaka ini masih banyak sarana prasarana yang belum memadai seperti perangkat komputer, printer yang masih minim, jaringan internet (Wifi) dan alat-alat yang terkadang bermasalah menjadi pelayanan di Kantor Kecamatan terhambat, pelayanan di Kantor Kecamatan Walantaka ini hanya menjadi pengantar untuk ke tempat tujuan masingmasing.

Disamping itu motivasi menjadi pendukung perilaku pegawai sehingga pegawai tersebut berkeinginan untuk bekerja keras dan antusias untuk mencapai hasil yang maksimal. Karena motivasi merupakan dorongan dari dalam atau dari luar diri seseorang untuk melakukan segala sesuatu kegiatan untuk mencapai tujuan ke arah yang lebih baik. Namun kenyataannya di dalam Kantor Kecamatan Walantaka ini kurang termotivasi, dapat terlihat dari masih adanya pegawai yang belum bisa menyelesaikan pekerjaan sesuai dengan jangka waktu yang telah ditetapkan. Hal ini terjadi akibat kurangnya 
dorongan motivasi pegawai dalam bekerja sehingga para pegawai di kecamatan tersebut kurang antusias untuk meningkatkan kinerjanya sehingga hasil dari pencapaian kinerja tidak seluruh nya maksimal.

Rumusan masalah dalam penelitian ini adalah:

1. Apakah Lingkungan Kerja Berpengaruh Terhadap Kinerja Pegawai Di Kantor Kecamatan Walantaka Kota Serang?

2. Apakah Motivasi Berpengaruh Terhadap Kinerja Pegawai Di Kantor Kecamatan Walantaka Kota Serang?

3. Apakah Secara Bersama-sama Lingkungan Kerja dan Motivasi Berpengaruh Terhadap Kinerja Pegawai Di Kantor Kecamatan Walantaka Kota Serang?

Wibowo dalam Surajiyo (2020) kinerja performance sebagai hasil kerja atau prestasi kerja. Namun sebenarnya kinerja mempunyai makna yang lebih luas, bukan hanya hasil kerja, tetapi termasuk bagaimana proses pekerjaan berlangsung.

Menurut Simajuntak dalam Harahap (2020) Faktor yang mempengaruhi kinerja. (1) kemampuan dan keterampilan melakukan kerja. Kompetensi seseorang dipengaruhi oleh beberapa faktor yang dapat dikelompokan dalam dua golongan yaitu kemampuan dan keterampilan kerja serta motivasi dan etos kerja. (2) Faktor dukungan organisasi, dalam melaksanakan tugasnya, pegawai memerlukan dukungan organisasi tempat iya bekerja. Dukungan tersebut adalah dalam bentuk pengorganisasian, penyediaan sarana dan prasarana kerja, kenyamana lingkungan kerja, pengorganisasian yang dimaksud untuk memberi kejelasan bagi setiap orang tentang sasaran yang harus dicapai dan apa yang harus dilakukan untuk mencapai sasaran tersebut. Setiap orang perlu memiliki dan memahami uraian jabatan dan tugas yang jelas. (3) Faktor dukungan manajemen, kinerja perusahaan dan kinerja setiap orang juga sangat tergantung pada kemampuan manajerial para manajemen atau pemimpin, baik dengan membangun sistem kerja dan hubungan industrial yang aman dan harmonis, maupun dengan mengembangkan kompetensi pekerja, demikian juga dengan menumbuhkan motivasi seluruh untuk bekerja secara optimal.

Bernardin \& Russel dalam Rusmaini (2019) untuk mengukur kinerja dapat digunakan beberapa indikator yaitu (1) Kualitas merupakan tingkatan dimana proses atau hasil dari penyelesaian suatu kegiatan mendekati sempurna. (2) Kuantitas merupakan jumlah suatu kegiatan yang telah diselesaikan (3) ketepatan waktu merupakan dimana kegiatan tersebut dapat diselesaikan. (4) Efektifitas biaya merupakan tingkatan sumber 
daya organisasi dapat memaksimalkan dan memperoleh keuntungan yang tinggi. (5) Hubungan perorangan merupakan perasaan saling menghargai, niat baik dan kerja sama antar karyawan.

Menurut Ahyari dalam Ferawati (2017) lingkungan kerja merupakan "lingkungan di mana para karyawan melaksanakan tugas dan pekerjaannya sehari-hari” dan menyatakan para karyawan juga memiliki keinginan psikologis yang harus dipenuhi agar karyawan dapat bekerja dengan baik. Sedarmayanti dalam Permadi (2017) menyatakan bahwa secara garis besar, jenis lingkungan kerja terbagi dua yaitu (1) Lingkungan Kerja Fisik adalah semua keadaan berbentuk fisik yang terdapat di sekitar tempat kerja yang dapat mempengaruhi pegawai baik secara langsung maupun secara tidak langsung. (2) Lingkungan kerja non fisik adalah semua keadaan yang terjadi berkaitan dengan hubungan kerja, baik hubungan dengan atasan, hubungan dengan rekan kerja ataupun hubungan dengan bawahan. Menurut Sedarmayanti dalam Sulistiawan (2011) indikatorindikator dari lingkungan kerja adalah sebagai berikut (1) Pencahayaan (2) Sirkulasi Udara (3) Suara Bising (4) Keamanan Kerja (5) Hubungan Pegawai.

Menurut B Uno dalam Rumbewas (2018) Motivasi adalah suatu dorongan yang timbul oleh adanya rangsangan-rangsangan dari dalam maupun dari luar sehingga seseorang berkeinginan untuk mengadakan perubahan tingkah laku atau aktivitas tertentu yang lebih baik dari sebelumnya. Menurut Sardiman dalam Sunarsi (2018) ada beberapa fungsi- fungsi dari terwujudnya suatu motivasi yaitu (1) Mendorong manusia untuk berbuat, jadi motivasi dalam hal ini merupakan penggerak dari setiap kegiatan yang akan dikerjakan. (2) Menentukan arah perbuatan, yakni ke arah tujuan yang hendak dicapai. Dengandemikian motivasi dapat memberikan arah dan kegiatan yang harus dikerjakan sesuai dengan rumusan tujuannya. (3) Menyeleksi perbuatan, yakni menentukan perbuatan-perbuatan apa yang harus di kerjakan yang serasi guna mencapai tujuan, dengan menyisihkan perbuatan yang tidak bermanfaat bagi tujuan tersebut.

\section{METODE PENELITIAN}

Jenis metode penelitian yang digunakan peneliti yaitu metode survey. Metode Survey adalah metode untuk mengumpulkan informasi dari kelompok yang mewakili sebuah populasi dengan terjun langsung kelepangan. Sedangkan untuk pengolah data yang digunakan peneliti yaitu pendekatan penelitian kuantitatif, penelitian kuantitatif adalah suatu metode penelitian yang bersifat induktif, objektif dan ilmiah dimana data 
yang diperoleh berupa angka-angka atau pernyataan-pernyataan yang di nilai, dan dianalisis dengan analisis statistik.

Dalam penelitian ini yang menjadi populasi adalah pegawai di Kantor Kecamatan Walantaka Kota Serang yang berjumlah 30 orang. Pengambilan sampel pada penelitian ini adalah menggunakan teknik sampel jenuh yang artinya jumlah populasi dijadikan sampel, sehingga peneliti menggunakan sampel sebanyak 30 responden.

Pengumpulan data yang digunakan oleh penulis untuk memperoleh data yang diperlukan dengan cara sebagai berikut:

1. Data Primer, adalah data yang diperoleh peneliti di lapangan. Seperti wawancara, observasi dan kuesioner.

a. Wawancara

Wawancara adalah percakapan yang memiliki tujuan untuk mendapatkan kontruksi yang terjadi sekarang mengenai : orang, kejadian, aktivitas, organisasi, perasaan, motivasi, pengakuan, kerisauan dan sebagainya. Lincoln dan Guba dalam Suwenda (2018).

b. Observasi

Observasi juga sebagai teknik pengumpulan data mempunyai ciri spesifik bila dibandingkan dengan teknik yang lain. Menurut Sutrisno Hadi dalam Sugiyono (2015) mengemukakan bahwa, observasi merupakan suatu proses yang kompleks, suatu proses yang tersusun dari berbagai proses biologis dan psikologis, dua diantara yang terpenting adalah proses-proses pengamatan dan ingatan.

c. Kuesioner (Angket)

Kuesioner yaitu pertanyaan/ pernyataan tertulis (bisa tertutup, terbuka atau setengah terbuka) untuk mendapatkan informasi dari responden.

2. Data Sekunder, adalah data yang dikumpulkan secara tidak langsung yang diperoleh dengan memanfaatkan hasil pengumpulan data pihak lain, misalnya profil kecamatan, Arsip Kecamatan.

3. Data Tersier, adalah data yang dikumpulkan dan diperoleh dari skripsi, tesis,disertasi, jurnal dan majalah ilmiah

Dalam penelitian ini menggunakan analisis data secara statistic deskriptif. Penggunakan metode ini digunakan untuk menggambarkan secara sistematis tentang 
fakta fakta serta hubungan antar variabel suatu dengan variabel lain. Uji validitas dan reliabilitas digunakan untuk mengukur instrument yang akan diukur dan reliable digunakan untuk mengetahui ketepatan satu ukuran. Uji asumsi klasik digunakan untuk pengujian terhadap uji normalitas, uji multikolinearitas dan uji heteroskedastisitas. Analisis regresi linear berganda digunakan untuk mengetahui pengaruh antara variabel bebas dengan variabel yang terikat. Analisis koefisien korelasi Analisis Koefisien Korelasi digunakan untuk mengetahui hubungan antara variabel independen secara bersama-sama dengan variabel dependen. Analisis Koefisien Determinasi digunakan untuk melihat presentase (\%) besarnya kontribusi (pengaruh) variabel X1, X2 terhadap variabel Y. Uji T digunakan untuk mengetahui pengaruh variabel independen yaitu Lingkungan kerja dan Motivasi secara parsial terhadap variabel dependen yaitu Kinerja pegawai. Uji $\mathrm{F}$ digunakan untuk menguji besarnya pengaruh dari seluruh variabel independen secara bersama-sama terhadap variabel dependen.

\section{HASIL DAN PEMBAHASAN}

Proses analisis data menggunakan regresi linier mengharuskan untuk melakukan uji asumsi klasik yang meliputi uji normalitas, heteroskedastisitas, dan multikolinieritas. Hasil uji normalitas data residual dapat dilihat pada Tabel 1 berikut.

Tabel 1 Uji normalitas Data

One-Sample Kolmogorov-Smirnov Test

\begin{tabular}{|c|c|c|}
\hline & & $\begin{array}{l}\text { Unstand } \\
\text { ardized } \\
\text { Residual }\end{array}$ \\
\hline \multicolumn{2}{|l|}{$\mathbf{N}$} & 30 \\
\hline \multirow[t]{2}{*}{ Normal Parameters ${ }^{\text {a,b }}$} & Mean & .0000000 \\
\hline & Std. Deviation & 3.34707597 \\
\hline \multirow[t]{3}{*}{ Most Extreme Differences } & Absolute & .110 \\
\hline & Positive & .097 \\
\hline & Negative & -.110 \\
\hline \multicolumn{2}{|c|}{ Test Statistic } & .110 \\
\hline \multicolumn{2}{|c|}{ Asymp. Sig. (2-tailed) } & $.200^{c, d}$ \\
\hline
\end{tabular}


d. This is a lower bound of the true significance.

Dari tabel diatas dapat dilihat bahwa One-Sample Kolmogorov- Smirnov Test atau Asymp sig. (2-tailed) 0,200>0,05 maka data terdistribusi normal.

Tabel 2 Uji Multikolinearitas

\begin{tabular}{|c|c|c|c|c|c|c|c|c|}
\hline & & & & efficients ${ }^{a}$ & & & & \\
\hline & & $\begin{array}{r}\text { Unsta } \\
\text { Coe }\end{array}$ & $\begin{array}{l}\text { ndardized } \\
\text { fficients }\end{array}$ & $\begin{array}{r}\text { Standardized } \\
\text { Coefficients }\end{array}$ & & & $\begin{array}{r}\text { Colli } \\
\text { Sta }\end{array}$ & $\begin{array}{l}\text { earity } \\
\text { istics }\end{array}$ \\
\hline & Model & B & Std. Error & Beta & $\mathbf{t}$ & Sig. & Tolerance & VIF \\
\hline 1 & (Constant) & 12.664 & 8.524 & & 1.486 & .149 & & \\
\hline & $\begin{array}{l}\text { LINGKUNGAN } \\
\text { KERJA }\end{array}$ & .680 & .148 & .650 & 4.584 & .000 & 1.000 & 1.000 \\
\hline & MOTIVASI & .085 & .068 & .178 & 1.254 & .221 & 1.000 & 1.000 \\
\hline
\end{tabular}

a. Dependent Variable: KINERJA PEGAWAI

Tabel diatas dapat di lihat bahwa nilai Variance Inflation Factor (VIF) variabel lingkungan kerja dan variabel motivasi adalah 1.000 yang berarti nilai Variance Inflation Factor $(\mathrm{VIF})<10$. Dilihat dari nilai tolerance yang berarti nilai tolerance $>0.1$ dengan demikian dari hasil pengolahan tersebut dapat disimpulkan bahwa dalam penelitian ini tidak terjadi multikolinearitas.

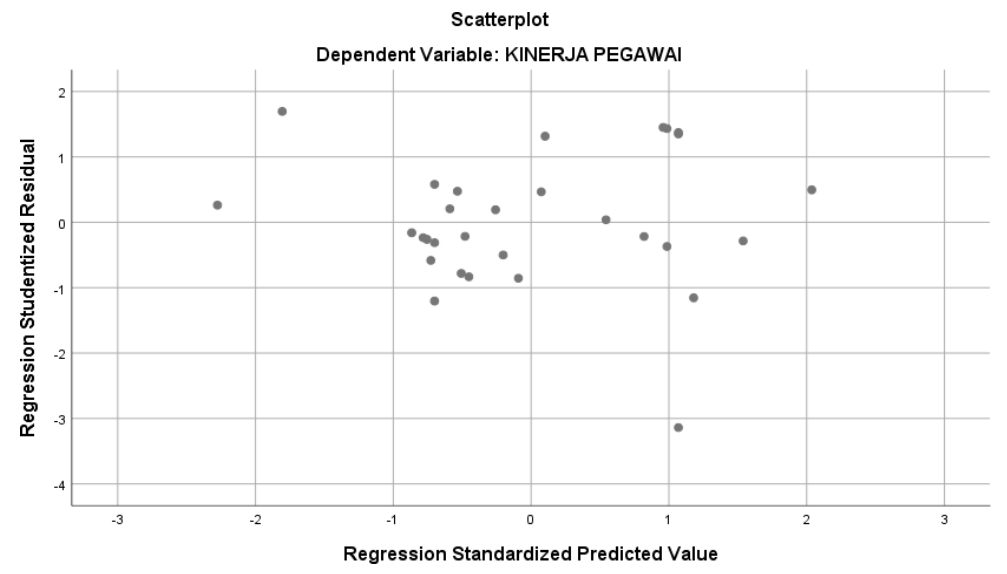

Gambar 1 Uji Heteroskedastisitas

Dengan melihat tampilan grafik diatas hasil Plot menunjukkan bahwa terlihat titiktitik menyebar secara acak serta tersebar diatas maupun dibawah 0. Hal ini menunjukan bahwa tidak terjadi heteroskedastisitas.

Tabel 3 Uji Regresi Linear Berganda

\section{Coefficients $^{\mathbf{a}}$}

\section{Unstandardize Standardized}




\begin{tabular}{|c|c|c|c|c|c|c|}
\hline \multirow{2}{*}{\multicolumn{2}{|c|}{ Model }} & \multicolumn{2}{|c|}{ Coefficients } & \multirow{2}{*}{$\begin{array}{l}\text { Coefficients } \\
\text { Beta }\end{array}$} & \multirow[t]{2}{*}{$\mathbf{t}$} & \multirow{2}{*}{ Sig. } \\
\hline & & B & $\begin{array}{l}\text { Std. } \\
\text { Error }\end{array}$ & & & \\
\hline \multirow[t]{3}{*}{1} & (Constant) & 12.664 & 8.524 & & 1.486 & .149 \\
\hline & $\begin{array}{l}\text { LINGKUNGAN } \\
\text { KERJA }\end{array}$ & .680 & .148 & .650 & 4.584 & .000 \\
\hline & MOTIVASI & .085 & .068 & .178 & 1.254 & .221 \\
\hline
\end{tabular}

b. Dependent Variable: KINERJA PEGAWAI

Berdasarkan hasil tabel diatas maka diperoleh persamaan sebagai berikut

$Y=12.664+0.680 X 1+0.085 X 2$

Keterangan :

$\mathrm{Y}=$ Kinerja Pegawai

X1= Lingkungan Kerja

$\mathrm{X} 2=$ Motivasi

Berdasarkan persamaan tersebut dapat diartikan sebagai berikut :

1. Apabila nilai konstanta sebesar 12.664 artinya nilai Lingkungan Kerja dan Motivasi adalah 0, maka nilai Kinerja Pegawai sebesar 12.664.

2. Nilai koefisien regresi variabel Lingkungan Kerja sebesar 0.680 mengalami kenaikan 1 maka variabel Kinerja Pegawai akan mengalami kenaikan 0.680. koefisien bersifat positif artinya terjadi hubungan yang positif antara Lingkungan Kerja denganKinerja Pegawai, semakin tinggi lingkungan kerja maka semakin meningkat kinerja pegawai.

3. Nilai koefisien regresi variabel Motivasi sebesar 0.805 artinya apabila variabel independen lain nilainya tetap dan Lingkungan Kerja mengalami kenaikan 1 maka Kinerja Pegawai akan mengalami keinaikan 12.664. koefisien bersifat positif artinya terjadi hubungan yang positif antara Motivasi dengan Kinerja Pegawai, semakin rendah Motivasi maka semakin menurun Kinerja Pegawai.

Tabel 4 Uji Koefisien Korelasi

Model Summary 


\begin{tabular}{cc|c|c|c|c}
$\begin{array}{c}\text { Mode } \\
1\end{array}$ & $\mathbf{R}$ & $\mathbf{R}$ & $\mathbf{R}$ & $\begin{array}{c}\text { Adjusted } \\
\text { the }\end{array}$ & $\begin{array}{c}\text { Std. Error of } \\
\text { Durbin- } \\
\text { Watson }\end{array}$ \\
\hline 1 & & Square & Square & Estimate & . \\
\hline
\end{tabular}

a. Predictors: (Constant), MOTIVASI, LINGKUNGAN KERJA

b. Dependent Variable: KINERJA PEGAWAI

Berdasarkan tabel diatas nilai korelasi sebesar 0.676. Dengan nilai korelasi sebesar 0.676 dan berdasarkan kriteria interpretasi koefisien korelasi, nilai korelasi yang berada pada rentang (0.60-0.799) adalah kuat antara lingkungan kerja dan motivasi terhadap kinerja.

Tabel 5 Koefisien Determinasi

\begin{tabular}{|c|c|c|c|c|}
\hline \multicolumn{5}{|c|}{ Model Summary } \\
\hline Model & $\mathbf{R}$ & R Square & $\begin{array}{c}\text { Adjusted } \\
\text { R } \\
\text { Square }\end{array}$ & $\begin{array}{l}\text { Std. Error of } \\
\text { the Estimate }\end{array}$ \\
\hline 1 & $.676^{a}$ & .457 & .417 & 3.46883 \\
\hline
\end{tabular}

Dari tabel diatas dapat dilihat bahwa nilai koefisien determinasi adalah sebesar $0.457 \times 100 \%=$ ini berarti sebesar 45,7\% variabel lingkungan kerja dan motivasi mempengaruhi variabel kinerja. Sisanya sebesar 54,3\% dipengaruhi oleh variabel lain yang tidak dimasukan ke dalam penelitian ini.

Tabel 6 Uji T (Parsial)

\begin{tabular}{|c|c|c|c|c|c|c|}
\hline \multicolumn{7}{|c|}{ Coefficients $^{\mathrm{a}}$} \\
\hline & \multirow[b]{2}{*}{ Model } & \multicolumn{2}{|c|}{$\begin{array}{c}\text { Unstandardized } \\
\text { Coefficients }\end{array}$} & \multirow{2}{*}{$\begin{array}{c}\text { Standardized } \\
\text { Coefficients } \\
\text { Beta }\end{array}$} & \multirow[b]{2}{*}{$\mathbf{T}$} & \multirow[b]{2}{*}{ Sig. } \\
\hline & & B & Std. Error & & & \\
\hline \multirow[t]{3}{*}{1} & (Constant) & 12.664 & 8.524 & & 1.486 & .149 \\
\hline & $\begin{array}{c}\text { LINGKUNGAN } \\
\text { KERJA }\end{array}$ & .680 & .148 & .650 & 4.584 & .000 \\
\hline & MOTIVASI & .085 & .068 & .178 & 1.254 & .221 \\
\hline
\end{tabular}

a. Dependent Variable: KINERJA PEGAWAI

Dengan menggunakan tes uji dua arah dan tingkat siginifikan sebesar nyata ( = 
$0,05 \%$ atau tingkat kepercayaan $95 \%$ dengan derajat bebas $(\mathrm{df})=\mathrm{n}-\mathrm{k}=30-2=28$ maka nilai t tabel yaitu 2,048.

Berdasarkan hasil nilai variabel lingkungan kerja $t_{\text {hitung }}$ 4,584.dan nilai $t_{\text {tabel }}$ sebesar 2,048 dan karena nilai $t_{\text {hitung }}$ lebih besar dari tabel $(4,584>2,048)$ dengan nilai signifikan $0.000<0.05$ maka $\mathrm{H}_{\mathrm{o}}$ ditolak dan $\mathrm{H}_{\mathrm{a}}$ diterima. Artinya terdapat pengaruh antara Lingkungan Kerja terhadap Kinerja Pegawai.

Dan berdasarkan hasil nilai variabel motivasi $t_{\text {hitung }} 1,254$ dan nilai $t_{\text {tabel }}$ sebesar 2,048 dan karena nilai $t_{\text {hitung }}$ lebih kecil dari $t_{\text {tabel }}(1,254<2,048)$ dengan nilai signifikan 0,221 > 0.05 maka $\mathrm{H}_{\mathrm{o}}$ dterima dan $\mathrm{H}_{\mathrm{a}}$ ditolak. Artinya tidak ada pengaruh antara Motivasi terhadap Kinerja Pegawai.

Tabel 7 Uji F (Simultan)

\begin{tabular}{|c|c|c|c|c|c|c|}
\hline \multicolumn{7}{|c|}{ ANOVA } \\
\hline & Model & $\begin{array}{l}\text { Sum of } \\
\text { Squares }\end{array}$ & Df & $\begin{array}{c}\text { Mean } \\
\text { Square }\end{array}$ & $\mathbf{F}$ & Sig. \\
\hline \multirow[t]{3}{*}{1} & Regression & 273.915 & 2 & 136.958 & 11.382 & $.000^{b}$ \\
\hline & Residual & 324.885 & 27 & 12.033 & & \\
\hline & $\begin{array}{c}\text { Tota } \\
\text { I }\end{array}$ & $\mathbf{5 9 8 . 8 0 0}$ & 29 & & & \\
\hline
\end{tabular}

a. Dependent Variable: KINERJA PEGAWAI

b. Predictors: (Constant), MOTIVASI, LINGKUNGAN KERJA

Berdasarkan tingkat keyakinan 5\% atau 0,05 diketahui nilai $\mathrm{F}_{\text {hitung }}$ sebesar 11.382 dan $F_{\text {tabel }}$ sebesar 3.35 maka $F_{\text {hitung }}=11.382>F_{\text {tabel }}=3.35$. Berdasarkan kriteria uji diatas dan hasil perhitungan maka dapat disimpulkan bahwa secara bersama sama $\mathrm{H}_{\mathrm{o}}$ ditolak dan $\mathrm{H}_{\mathrm{a}}$ diterima artinya Lingkungan kerja dan Motivasi berpengaruh terhadap Kinerja Pegawai.

\section{PEMBAHASAN}

Lingkungan kerja di dalam Kecamatan Walantaka masih kurang memadai salah satunya suara bising dari jalanan cukup menggangu pekerjaan pegawai karena Kecamatan Walantaka bertempat di jalan utama Ciruas-Petir. Selain itu beberapa ruang kerja terdapat ruangan yang sempit sehingga mengganggu kenyamanan aktifitas para pegawai dalam melaksanakan pekerjaannya karena sirkulasi udara yang kurang hal ini mempengaruhi 
kinerja pegawai. Maka dari itu lingkungan kerja yang mendukung adalah suatu hal yang di inginkan oleh para pegawai untuk mendukung dan membantu pekerjaan pegawai agar lebih mudah dari segi lingkungan fisik ataupun lingkungan non fisiknya. Hal lain juga di Kecamatan Walantaka juga kurang nya alat alat kerja yang dapat membantu pegawai dalam melaksanakan pekerjaannya, sehingga Lingkungan Kerja ini dapat berpengaruh terhadap Kinerja pegawai.

Hal ini juga sejalan dengan penelitian Hendry Wijaya dan Emy Susanty (2017) yang menyebutkan bahwa hasil penelitiannya Lingkungan Kerja berpengaruh terhadap Kinerja Pegawai dengan hasil uji Thitung 5.636 > Ttabel 2.026. Dalam hal ini dapat dilihat pada tabel 4.32 bahwa dalam penelitian ini diperoleh hasil uji Thitung 4,584 > Ttabel 2,048 sehingga dapat disimpulkan bahwa Lingkungan Kerja berpengaruh terhadap Kinerja pegawai

Motivasi di Kecamatan Walantaka ini kurang optimal sehingga tidak berpengaruh terhadap Kinerja pegawai, karena kebutuhan fisik seseorang hakikatnya sama namun pegawai di Kecamatan Walantaka ini yang berstatus Honorer lebih banyak dari Pegawai Negri Sipil. Dalam hal tersebut Motivasi antara Pegawai Negri Sipil dan Pegawai Honorer jelas berbeda karena adanya diskriminasi sehingga motivasi tidak berpengaruh terhadap Kinerja Pegawai di Kantor Kecamatan Walantaka.

Hal ini sejalan dengan penelitian Nur Hasmalawati (2018) yang menyebutkan bahwa Motivasi tidak berpengaruh terhadap Kinerja pegawai dengan hasil nilai Signifikansi 0,489>0,05. Dalam hal ini dapat dilihat pada tabel 4.33 yang menunjukan bahwa nilai signifikansi 1,254>0,05 sehingga dapat disimpulkan bahwa Motivasi tidak berpengaruh terhadap Kinerja Pegawai.

Secara simultan Lingkungan Kerja dan Motivasi berpengaruh terhadap Kinerja Pegawai di Kantor Kecamatan Walantaka karena didalam suatu instansi tersebut Lingkungan Kerja dan Motivasi saling mendukung untuk meningkatkan hasil Kinerja Pegawai di Kantor Kecamatan Walantaka.

\section{KESIMPULAN DAN SARAN}

Berdasarkan hasil penelitian tentang Pengaruh Lingkungan Kerja dan Motivasi terhadap Kinerja Pegawai di Kantor Kecamatan Walantaka Kota Serang, akhirnya dapat penulis simpulkan sebagai berikut:

1. Lingkungan Kerja berpengaruh terhadap Kinerja Pegawai. Hal ini dibuktikan 
dengan hasil perhitungan uji $\mathrm{T}$. Diketahui nilai $t_{\text {hitung }} 4,584$ dan nilai $t_{\text {tabel }}$ sebesar 2,048 dan karena nilai thitung lebih besar dari $t_{\text {tabel }}(4,584>2,048)$ dengan nilai signifikan $0.000<0.05$ maka $\mathrm{H}_{\mathrm{o}}$ ditolak dan $\mathrm{H}_{\mathrm{a}}$ diterima. Artinya terdapat pengaruh antar Lingkungan Kerja terhadap Kinerja Pegawai.

2. Motivasi tidak ada pengaruh terhadap Kinerja Pegawai. Hal ini dibuktikan dengan hasil perhitungan uji T. Diketahui nilai thitung 1,254 dan nilai tabel sebesar 2,048 dan karena nilai thitung lebih kecil dari tabel $(1,254>2,048)$ dengan nilai signifikan 0,221 >0.05 maka $\mathrm{H}_{\mathrm{o}}$ dterima dan $\mathrm{H}_{\mathrm{a}}$ ditolak. Artinya tidak ada pengaruh antara Motivasi terhadap Kinerja Pegawai.

3. Secara simultan dengan tingkat kepercayaan sbesar $5 \%$ atau 0,05 di peroleh nilai $F_{\text {tabel }}$ sebesar 3.35 dari hasil perhitungan diperoleh nilai $F_{\text {hitung }}$ sebesar 11.382 maka dilakukan perbandingan antara nilai $F_{\text {hitung }}$ 11.382>3.35. Berdasarkan kriteria pengujian diatas dari hasil perhitungan, dapat disimpulkan bahwa secara bersama sama Lingkungan Kerja dan Motivasi berpengaruh terhadap Kinerja Pegawai.

Berdasarkan hasil dan pembahasan penelitian dan kesimpulan yang diambil dalam penelitian dan kesimpulan yang diambil dalam penelitian ini, maka peneliti memberikan saran sebagai berikut :

1. Sebaiknya instansi merekrut atau menambah pegawai baru karena didalam instansi sumber daya manusia yang minim.

2. Sebaiknya disetiap ruangan kerja diberi pendingin udara (AC/Kipas angin) agar disemua ruangan kerja terasa nyaman.

3. Sebaiknya sarana dan prasarana seperti printer, komputer ditambah agar tidak menghambat proses kerja pegawai dan pelayanan publik maksimal.

4. Sebaiknya pemimpin lebih memotivasi lagi pegawainya agar dalam menyelesaikan kinerja tidak menunda nunda sehingga program kerja dapat tercapai lebih baik.

\section{UCAPAN TERIMAKASIH}

Penulis mengucapkan terimakasih kepada Allah SWT yang telah memberikan rahmat dan kemampuan sehingga penelitian ini dapat terselasaikan dengan baik. Penulis juga mengucapkan terima kasih yang sebesar-besar kepada kepada Tim Panitia NCBET yang telah menginisiasi acara yang sangat bermanfaat ini. 


\section{DAFTAR PUSTAKA}

Hermawan, Irwan. 2019. “Metodologi Penelitian Kuantitatif, Kualitatif dan Mixed Methode". Kuningan : Hidayatul Quran.

Sugiyono.2015. "Metode Penelitian Kuantitatif, Kualitatif dan R\&d”. Bandung: Alfabeta.

Surajiyo,dkk. 2020. "Penelitian Sumber Daya Manusia, Pengertian, Teori Dan Aplikasi (Menggunakan IBM SPSS 22 FOR WINDOWS)”. Yogyakarta : CV. Budi Utama. Suwenda, I Wayan. 2018. “Metode Penelitian Kualitatif Dalam Ilmu Sosial, Pendidikan, Kebudayaan dan Kegamaan”. Bandung : Nilacakra. 